\title{
CP-Extraposition as Argument Shift
}

\author{
Josef Bayer \\ Friedrich-Schiller-Universität Jena
}

\section{Introduction}

The order of constituents has always been an important topic in generative grammar. While order had to be encoded in rules in a rather stipulative way, it was later taken to be a matter of parameterization. The issue of order has recently been re-addressed in a novel way by Kayne (1993). Kayne's claim is that c-command must be asymmetrical because c-command relations must map into linear order. Unique ordering allows either the order SPECIFIER HEAD COMPLEMENT or the order COMPLEMENT HEAD SPECIFIER. Kayne suggests that only the former is a legitimate option. If he is right, this has massive consequences for the analysis of languages that show head final order in the surface. In languages in which the visible order is SPECIFIER COMPLEMENT HEAD, the complement is always raised to some specifier position that, according to Chomsky's (1993) Minimalist Program, must have strong features. In this case variable order of constituents would be the result of feature strength, not of a parametrical choice. The goal of the present contribution is to show that this predicts greater homogeneity between head final and head initial languages than is actually observed. I will show how some of the advantages of Kayne's analysis can be captured by a more conservative approach in which order is still a matter of parametrical choice. I will in particular show that CP-extraposition in a subset of head final languages results from the deletion of the object position to the left of the verb. A CP that is related to this position by adjunction to VP becomes strongly L-related in the process of the derivation. This "re-selection" of CP disturbs the head-finality parameter which the language follows. The resulting order $[\mathrm{vp} \ldots \mathrm{V}$ $\mathrm{CP}$ ] turns VP into a barrier for movement from the non-canonically licensed Aposition related to $\mathrm{V}^{1}$. 


\section{Classical extraposition}

Following traditional wisdom according to which languages like Bengali, Dutch, Hindi, German, Turkish etc. are underlyingly OV-languages which nevertheless show $\mathrm{CP}$-complements to the right of the matrix verb, the classical analysis has been in terms of rightward movement. As shown in (1), the sentential complement of the verb originates in a canonically selected position where it is theta-marked. For some reason, such as Case Resistance, (Stowell 1981) it undergoes movement. Since the inflectional head follows VP in these languages, rightward movement must be adjunction to IP as shown in (1b):

(1) a. D-structure

$\left.\left[\mathrm{TP} \ldots\left[\begin{array}{l}\mathrm{I}^{\prime} \\ {[\mathrm{VP}}\end{array} \ldots \mathrm{CP} \mathrm{V}\right] \mathrm{I}\right]\right]$

b. S-structure (or PF)

$\left.\left[\mathrm{IP}\left[\mathrm{IP} \ldots\left[\begin{array}{l}\mathrm{Y} \\ \mathrm{VP}\end{array} \ldots \mathrm{e}_{\mathrm{i}} \mathrm{V}\right] \mathrm{I}\right]\right] \mathrm{CP}_{\mathrm{i}}\right]$

Various problems have been noticed in connection with this kind of extraposition operation. Those which are mentioned here may only be a subset. Notice first that from the perspective of the Minimalist Program movement to the right is unmotivated. There is no evidence of a functional head to the right whose specifier position is a landing site for checking features of CP. Case Resistance cannot be the reason either because German tolerates infinitives in situ and Bengali and various other head final languages systematically show CP-complements in situ which in addition must not undergo extraposition. Notice secondly a conceptual problem: in German, Wh-movement must be performed before CP is extraposed or from a reconstructed position; otherwise there would be movement from an island. Extrinsic rule ordering, however, has been banned from grammar for good reasons. Thirdly, all kinds of CPs (and other phrases) should extrapose, but in fact some never do. Consider the following examples from Bengali.
(2) a.
$\begin{array}{ll}\text { chele-Ta } & \text { Ilor } \\ \text { boy-CL his }\end{array}$
baba aS-be]
bole] Sune-che
boy-CL his father come-3FUT
COMP hear-PAST3
'The boy heard that his father will come'
b. [lor baba aSbe] bolel cheleTa Suneche
c. *cheleTa Suneche [Ior baba aSbe] bole]

The clause headed by the final complementizer bole can stay in situ or scramble to the left, but it must not undergo extraposition, whereas clauses headed by the element je must appear in extraposed position, as shown in (3).
(3) a.
chele-Ta Sune-che
lje lor
$b a b a$
aS-be]l
boy-CL hear-PAST3 COMP his
father come-3FUT 
b. *cheleTa [je lor baba aSbe]] Suneche

c. *[je Ior baba aSbel] cheleTa Suneche

As I have pointed out in Bayer (1995 in press), CPs must be licensed according to their inner architecture: COMP-final CP must be to the left of V, and COMPinitial CPs must be to the right of $\mathrm{V}^{2}$. Notice in addition that bole must be $[+\mathrm{V}]$, and as such it should - contrary to fact - undergo extraposition according to Case Resistance. Adjunction of CP to IP leads to a fourth problem: Unless reconstruction can be invoked, the binding relations seen in (4) and (5) are unexpected:

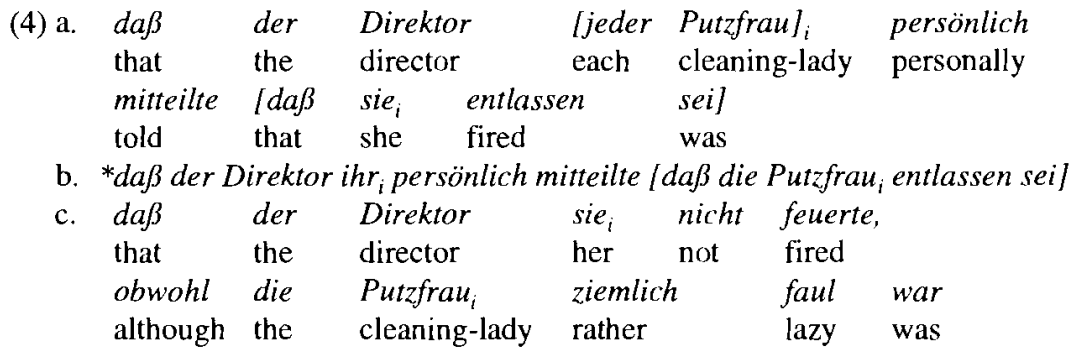

In (4a), sie can be interpreted as a variable bound by the indirect object jeder Putzfrau. Thus, CP must be c-commanded by the indirect object. Adjunction to IP, however, destroys the necessary relation. The same thing can be shown in (4b) where, contrary to expectation, a Principle C effect appears. Thus, the "name" die Putzfrau must be bound by the pronoun sie. Obviously the clause headed by obwohl in (4c) is attached high enough to void a Principle $\mathrm{C}$ effect. Notice that the bound variable reading appears also in Bengali, as shown in (5). This means that even in this rather strict head final language the CP complement cannot have been right adjoined to IP:

$$
\begin{aligned}
& \text { ami prottek-Ta chele }-k e_{i} \text { bole-chi } \\
& \text { I } \text { each }_{\mathrm{Cl}} \text { boy -oBJ say } \text { PASTI } \\
& l_{C P} \text { je Ekjon take }{ }_{1} \text { durga pujo-y notun } \\
& \begin{array}{clll}
\text { comP } & \text { someone him Durga Puja } \\
\text { jamak kapor } & \text { de-bel new }
\end{array} \\
& \text { clothes give-FUT3 }
\end{aligned}
$$

The c-command problem reappears in sentences in which a focusing particle like only or even must associate with a focused constituent (marked with capitals) in the extraposed CP. 


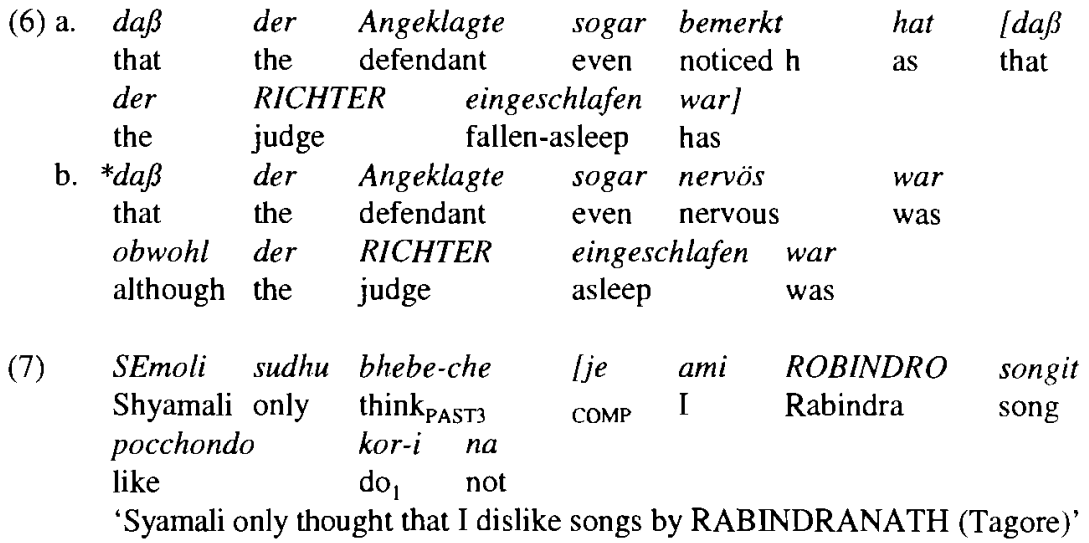

Focus association requires c-command. The obwohl clause in (6b) is ill-formed because sogar does not c-command the focus. In (6a) and in the Bengali example (7), however, the focus constituent is c-commanded. This is again unexpected in the classical extraposition account.

\section{SVO as basic order}

Following Kayne (1993), Zwart (1993) explicitly argues for SVO as the underlying order of Dutch. His analysis carries over to German. In Zwart's analysis the problems mentioned in 1 disappear: We do not need to worry about a motivation for rightward movement because the $\mathrm{CP}$ originates as a righthand complement of the verb anyway. Since CP is in an L-marked position, Whmovement from CP is expected. While DPs and certain other phrases move to the left in visible syntax (before Spell-Out), CPs stay in situ because the heads which check them may have weak features. Thus CP-movement is postponed till LF. Since the CP is lower than the potential binder or the focusing particle, the CP is always lower than the potential binder, and the binding problem and the focus association problem disappear. In the Minimalist analysis a transitive sentence of the form S-V-AUX-CP (e.g. ... daß er gesagt hat daß ...) now has the structure in (8): 
(8)

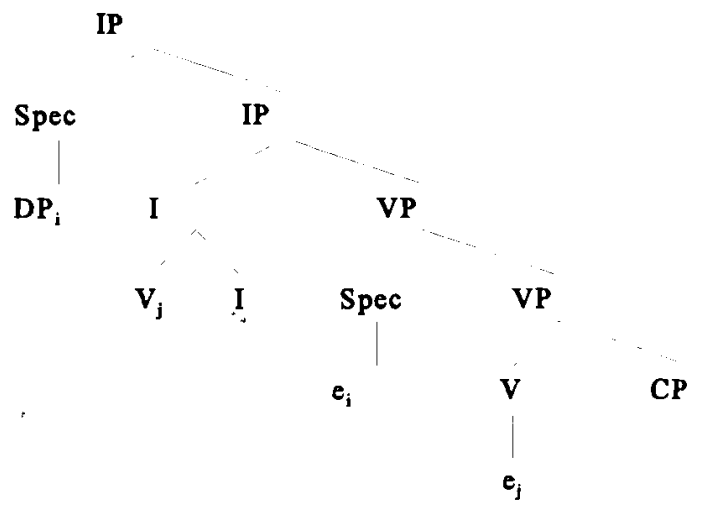

It appears that this analysis also makes the right predictions for abstract Wh-scope in Chinese and for Wh-movement in Hindi. Consider the following data which are drawn from Cheng (1991) and Srivastav (1991b) respectively:

$\begin{array}{lllll}\text { huangrong } & \text { xiangxin } & \text { goujing } & \text { mai-le sheme } \\ \text { Huangrong } & \text { believes } & \text { Guojing buy } & \text { ASP } & \text { what } \\ \text { 'What does Huangron believe that Guojing bought?' }\end{array}$

(10) kyaa ${ }_{i}$ tum jante ho $I_{C P}$ ki usNE e kiyaa]?

what you know $A U X$ that he did

'What do you know that he did?'

Let us for simplicity assume that $W h$-features are weak in Chinese, while they may be strong or weak in Hindi (which is normally a $W h$-in-situ language). In this case we could expect that sheme moves after Spell-Out, while kyaa may move before Spell-Out. In each case movement is predicted to be possible because the CPcomplement is in a properly selected and L-marked position. I will in the following sections point to a number of facts which show that the world is a trifle more complicated than that.

\section{Long $W h$-scope in $W h$-in-situ languages}

It has repeatedly been observed in the last few years that there is no LF-movement from the extraposed $k i$-clause in Hindi ${ }^{3}$.

$$
\begin{aligned}
& \text { tum jante ho } I_{C P} k i \text { usNE kyaa kiyaal? } \\
& \text { you know AUX COMP he what did } \\
& \text { i. You know what he did } \\
& \text { ii. } \quad \text { NOT: What do you know that he did? }
\end{aligned}
$$


In the classical extraposition account one could say that the CP in (11) is in an $\mathrm{A}^{\prime}$ position; thus LF-movement into the matrix clause is not possible, and consequentially only the narrow scope reading is derived. Cases of overt movement as seen in (10) must then be the result of $W h$-movement and subsequent extraposition of the remnant $\mathrm{CP}^{4}$. This approach is troubled by the fact that the $\mathrm{ki}$ clause does not seem to be in a derived position; furthermore, the grammar of Hindi would have to make reference to extrinsic rule ordering. In order to shed more light on this issue let me turn to data from Bengali and Marathi both of which are closely related to Hindi. Both languages have finite CPs in extraposed position, but they differ from Hindi in also showing finite CP which cannot extrapose but must always remain to the left of the verb (see (2) for Bengali). Consider first what we can observe about the scope of $W h$-in-situ in Bengalis

ora Sune-che lke aS-be]
they hear
i.
ii. They heard who will come

(13)

ora l[ke aS-be] (bole)] Sune-che
they who come
i.
ii. They heard who will come
ii. Whar

The datum in (12) echoes what we saw in example (11) from Hindi: Only narrow scope of the Wh-operator is allowed. (13), however, shows scope ambiguity. Besides the indirect question interpretation, it can be understood as a direct question $^{6}$. Consider next the Bengali data in (14) and the Marathi data in (15) which are taken from Wali (1988):

(14) a. tumi lke bari kor-bel bhab-cho? you who house make-FUT3 think-2

Who do you think will build a house?

b. *tumi bhabcho [ke bari korbe]

(15) a. minila [lilini ravila kay dila] asa vatta Mini Lili to-Ravi what gave comp believes 'What does Mini believe that Lili gave to Ravi?'

b. *minila vatta [ki [koni pustak vacla]]

Mini believes сомp who book read

Obviously the lexical items corresponding to "think" or "believe" do not permit an interrogative complement ${ }^{7}$. This is shown by the ungrammaticality (violation of s-selection) of (14b) and (15b). Since (14a) and (15a) are grammatical, the Whoperator must have been able to move to a landing site in the matrix clause. It is 
important to see that $W h$-scope in these languages is exclusively determined by movement. There is no indication of a $W h$-scope marker like in Japanese or Chinese which could determine the assignment of scope ${ }^{8}$.

These data contribute in a remarkable way to the present discussion about the order of constituents: Although the object-CP seems to occupy an A-position inside VP, this CP turns out to be a strict scope island. The wide scope option seen in Bengali and Marathi is obviously connected to the fact that these languages permit CPs to occur in a canonically selected object position to the left of the verb as suggested by the head-finality parameter. This is not what is expected in Kayne's (1993) and Zwart's (1993) theory of a universal SVO-base. Recall that in their proposal the notion directionality of government or directionality of selection has no meaning. Je-clauses and $k i$-clauses are in the only position in which complements can ever arise. Once long $W h$-movement is postponed after Spell-Out as is the case in these languages, Bengali, Hindi and Marathi should not differ from Chinese ${ }^{9}$.

\section{On the scope of only}

Consider next sentences that involve phrases which are modified by or quantified with focusing particles such as only and even. In this area, we find a surprising ambiguity that is normally absent in QR processes: A focusing particle that occurs in the embedded clause may obtain scope over the matrix clause. Example (16a) is taken from Taglicht (1984); according to native speakers of English, even (16b) is ambiguous as long as the embedded clause appears with subjunctive mood:

(16) a. We are required to study only SYNTAX

b. It was required that we study only SYNTAX

i. It was required that we study nothing but syntax i.e., studying other subjects was forbidden

ii. Nothing was required to study but syntax i.e., studying other subjects was still permitted

Obviously, the phrase only SYNTAX has been moved to some operator position in the matrix clause in order to achieve the wide scope reading shown in (16ii). Notice now that this wide scope reading is strictly impossible in German (the impossible reading is marked with \#):

(17) a. Man hat uns gezwungen nur SYNTAX zu studieren

b. Es wurde verlangt, daß wir nur SYNTAX studieren

i. One has forced us to study nothing but syntax / It was required that we study nothing but syntax i.e. studying other subjects was forbidden 
ii. \#Nobody has forced us to study anything but syntax / Nothing was required to study but syntax i.e., studying other subjects was still permitted

The same effect arises in the following comparison between Italian and German. According to Longobardi (1991), the sentence in (18) is ambiguous between narrow and wide scope construal of solo. Again, the German translation in (19) entirely lacks the wide scope construal of nur:

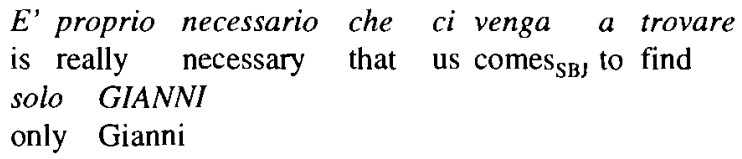

(19) a. Es ist nötig, daß uns nur GIANNI besucht

b. Es wurde verlangt, daß uns nur GIANNI besuchen solle

i. the others must not come

ii. \#the others need not come

The contrast that is observed here cuts along the lines of head initiality as exemplified by English and Italian, and head finality as exemplified by German. It is unclear how this result can be achieved in a theory that assigns a VP containing (clausal) complements the same basic structure across languages: Given that the licensing of CPs to the right of a matrix predicate remains the same, it is expected that nur SYNTAX or nur GIANNI are subject to the same options of construal as their English and Italian counterparts.

Let us consider now a further difference. This difference has to do with the fact that a $\mathrm{CP}$ which is itself quantified with a focusing particle must undergo movement to an operator position for the particle to gain scope over the matrix clause. Notice that the sentences in (20) which are taken from Iatridou and Kroch (1992) must get roughly the semantic representation shown in (21):

(20) a. He asked [only [what John ate]

b. He said [only [that John is sick]

(21) a. For every question $q$ from the set of questions $\{Q\}$, if he asked $q$, then $q=$ $\lambda \mathrm{x}$, John ate $\mathrm{x}$

b. For every proposition $p$ from the set of propositions $\{P\}$, if he uttered $p$, then $\mathrm{p}=\mathrm{John}$ is sick 
According to the theory developed in Bayer (in press), the appropriate LF is achieved by moving the entire phrase [only $\mathrm{CP}$ ] to the specifier of an abstract head $\mathrm{Prt}^{\circ}$ to the left of the matrix VP in the course of which $\mathrm{Prt}^{\circ}$ is identified as only. In this way the particle obtains scope over the matrix clause. Since movement always leaves a copy behind (Chomsky 1993), CP may be deleted in SpecPrtP, while the operator only will be deleted in its underlying position. Thus the LF is as in (22):

$$
\text { ... [PrrP onty } \mathrm{CP}\left[\left[_{\mathrm{Pr}^{\prime}}\left[\mathrm{Prr}^{\circ} \text { only }\right]\left[_{\mathrm{VP}} \mathrm{V} \text { onty } \mathrm{CP}\right]\right]\right.
$$

The same process must be available in Italian as the following example shows:

$$
\begin{aligned}
& \text { Mia madre mi ha chiesto per telefono [solo } \\
& \text { my mother me has asked by telephone only } \\
& \text { [se avessi passato l'esame]] } \\
& \text { whether (I) had passed the exam } \\
& \text { 'The only thing my mother asked me on the phone was whether I had passed } \\
& \text { the exam' }
\end{aligned}
$$

Notice now that German sentences that correspond to (20) and (23) are completely unacceptable, while all of them are perfect if the particle appears before the matrix VP:

(24) a. *weil ich gefragt habe [nur was Hans gegessen hat]

b. *weil er gesagt hat [nur daß Hans krank ist]

c. *weil mich meine Mutter am Telefon gefragt hat lnur ob ich das Examen bestanden hätte]

(25) a. weil ich nur gefragt habe [was Hans gegessen hat]

b. weil er nur gesagt hat [daß Hans krank ist]

c. weil mich meine Mutter am Telefon nur gefragt hat lob ich das Examen bestanden hätte]

The correct generalization seems to be that [only/solo/nur $\mathrm{CP}$ ] is forced to move to a scope position as shown in (22), but that this movement is possible in English and Italian but not in German. The only way out for German is to base generate nur in the head position Prt ${ }^{\circ}$ of the matrix clause. It can easily be shown that the ungrammaticality of the German examples in (24) is connected to the fact that the quantified $\mathrm{CP}$ is an argument of the verb. To see this, consider the sentence in (26) which is linearly identical to those in (24), but nevertheless grammatical: 


weil die Kinder geweint haben [nur wenn die Eltern
because the children wept have only if the parents
weggehen wollten]
leave wanted
'Because the children wept only if the parents wanted to leave'

The wenn-clause is an adjunct. Nur must achieve scope over the matrix clause as usual. This seems to be possible under the condition that it affects a clause with adjunct status.

The data considered in this section are again unexpected in a theory that takes German CPs with argument status to originate in a canonical position to the right of the verb. While English and Italian permit movement of a phrase quantified with a focusing particle to a scope position to the left of the matrix-VP, such movement seems to be strictly impossible in German. The only promising road to an explanation of this difference seems to rest in the parametric difference according to which the verb governs to the right in English and Italian while it governs generally to the left in German. Given the earlier findings which militate against the classical extraposition approach, we are now in a dilemma: On the one hand, an argument-CP must be in VP in order to be c-commanded from material in the matrix-CP. On the other hand, an argument-CP to the right of $\mathrm{V}$ seems to be an island for LF-movement, and it seems to be impossible to move this CP itself to any higher position. In the next section, I will show a way to resolve this dilemma.

\section{Extraposition as Argument Shift}

The extraposition problem lies in the representation that connects the extraposed material with a trace in the canonical object position. According to Büring and Hartmann (1994), where such an approach is defended, the extraposed CP could be reconstructed into its original position, but then it is unclear why the phrase [nur CP] in (24) should fail to achieve a scope position ${ }^{10}$. Consider therefore an alternative approach to extraposition that was proposed by Hoekstra (1987). Hoekstra considers the role of traces in the theory of movement, and observes that the primary reason for their presence is the requirement that the Projection Principle be satisfied on all levels of representation. If it were not for the Projection Principle, traces could delete as well. The lexically induced relation between head and complement would then have to be recoverable in the output of the transformation. Consider the structure in (27), in which XP is taken to be the maximal projection of $X$; for the purpose of this introduction, we ignore the trace of an XP-internal subject: 
(27)

$$
\left[X P\left[{ }_{X P} e_{i} X\right] Y P_{i}\right]
$$

If the trace $e_{i}$ is deleted, the Projection Principle is at first look violated because $\mathrm{X}$ cannot discharge its $\theta$-role, and the shifted phrase $\mathrm{YP}$ is unlicensed. On closer inspection, however, it emerges that $\mathrm{YP}$ remains in the projection of $\mathrm{X}$. With deletion of the trace, $\mathrm{X}$ cannot project to $\mathrm{X}^{\prime}$ and $\mathrm{XP}$; but now there is the required object in the next projection up. Since deletion of the trace has pruned XP to $X^{\circ}$, $X$ will now again bear a head relation to the $Y P$ on its righthand side. As far as the Projection Principle is concerned, $\left[{ }_{X P}\left[{ }_{X P} X\right] Y P\right]$ is formally identical to $\left[{ }_{X P} X\right.$ YP]. This latter structure equals one in which $X$ simply selects $Y P$ to the right, and $\mathrm{YP}$ is included in XP. I wish to call this operation argument shift because the extraposed $\mathrm{CP}$ does not move to an $\mathrm{A}^{\prime}$-position but rather ends up in a configuration in which its bears again a direct object relation to the verb.

A problem may be seen in the fact that in real examples the shifted CP does not attach to VP but to IP. Notice that any number of auxiliaries and modals may intervene between $\mathrm{V}^{\circ}$ and $\mathrm{CP}($ daß er sagen können müßte $[d a \beta \ldots]$, 'that he should be able to say that ...'). This problem is only apparent, however. There is independent evidence that auxiliaries and modals trigger verb raising, i.e. the main verb will incorporate into the next higher AUX/MOD verb, and this complex may again incorporate into the next higher AUX/MOD verb. According to Baker's (1988:64) Government Transparency Corollary (GTC), a lexical category which has incorporated some lexical item governs everything the incorporated item had governed in its original position. If the GTC holds, we are entitled to assume a direct government relation between $\mathrm{V}^{\circ}$ and $\mathrm{CP}$ despite the fact that the two may be linearly separated by other verbs. The preconditions for this to work are first that there is head movement from V to AUX/MOD and secondly that the original traces of $\mathrm{V}^{\circ}$ and $\mathrm{CP}$ are deleted. Let us, for reasons of introduction, assume that there is only one step of head movement, namely V-to-I raising. In this case, CP could be right-adjoined to I'. Trace deletion leads to the output shown in (28):

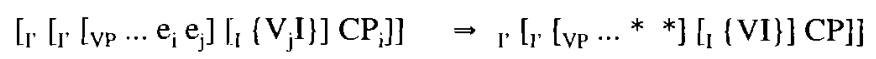

Adjunction to an non-maximal and non-minimal category as in (28) can be avoided if we assume that before Spell-Out inflected verbs are inserted as plain verbs which undergo movement to the functional positions subsumed under "I" post Spell-Out. If this solution is tenable, CP can simply be attached to VP. If the Case checking mechanism of the Minimalist Program is adopted, all the arguments must have left VP at the latest at LF. This means that the extraposed CP will be in the c-command domain of arguments to the left of the verb. As the data in (4) through (7) have shown, this is a desirable result. Assuming VP-internal subjects, the trace of the subject may likewise delete; $V$ and $C P$ end up in a sisterhood relation, i.e. adjunction of $\mathrm{CP}$ to VP equals direct licensing of $\mathrm{CP}$ by $\mathrm{V}^{\circ}$. If 
$\mathrm{V}$-movement to functional positions can be procrastinated, the $\mathrm{LF}$ of a transitive sentence of the form $\mathrm{DP}_{\mathrm{SU}^{-}}$V-AUX-CP will look as in (29):
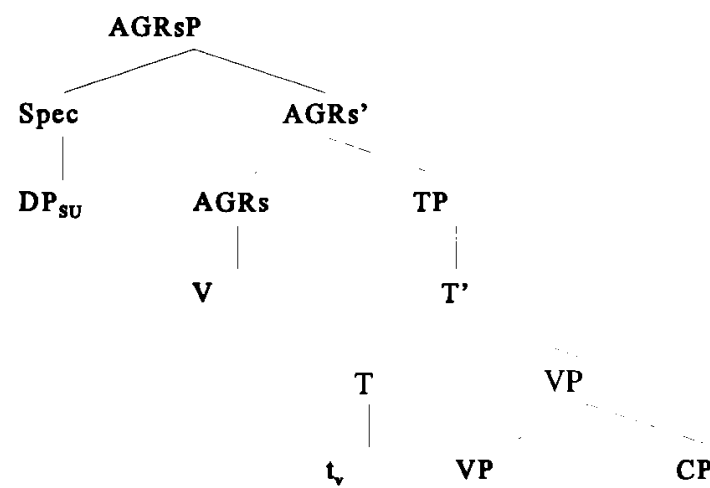

Once the verb has been raised to $\mathrm{T}$ and AGRs, it may $\theta$-mark the subject-DP that its presence in the underlying position is not necessitated ${ }^{1 !}$.

Many questions are connected with this proposal. One such question is why argument shift should exist at all. Within the Minimalist Program, for instance, there seems to be no reason for rightward movement to apply. Thus, why should a Bengali or German CP extrapose if its underlying position is to the left of the verb in agreement with Baker's (1988) Uniformity of Theta Assignment Hypothesis (UTAH)? For reasons of space I cannot address this question here, but see Bayer (in press) for some preliminary ideas. With respect to the present focus on CPs with direct object status, however, rightward movement can obviously be dispensed with. To see this, one should be aware of the fact that in place of the trace there can be a lexical element. In German this would be the pronoun es, in Bengali it would be the pronouns $t a$ or the demonstrative $e T a$ ("this") or a dummy DP like $e$ kotha (literally "this speech"), in Hindi the demonstrative yeh or the dummy DP yeh baat ("this matter"). Consider now the possibility that instead of moving $\mathrm{CP}$ to the right and the deleting the trace as envisaged by Hoekstra, $\mathrm{CP}$ is 
base adjoined to a VP in which the direct object position is occupied by an expletive of this sort. This element normally receives the object $\theta$-role and object (or accusative) Case, while the base adjoined and coindexed $\mathrm{CP}$ receives the $\theta$ role only by inheritance ${ }^{12}$. We can now proceed with the analysis as before and argue that in the course of the derivation the expletive element is deleted ${ }^{13}$. What is the difference between the two analyses? The main prediction is that in head final languages with CP-extrapositions that use this mechanism, the extraposed $\mathrm{CP}$ has never been to the left of the verb. The structure of German seems to contradict this prediction directly because we do find $d a \beta$-clauses to the left of the matrix verb, either in scrambled or in topicalized position:

$$
\begin{aligned}
& \text { (30) a. Peter hätte } I_{C P} \text { daß er die anderen für Deppen hält] nicht } \\
& \text { Peter had }{ }_{\mathrm{SB}} \text { that he the others for idiots takes not } \\
& \text { so laut sagen sollen } \\
& \text { so loudly say should } \\
& \text { 'Peter should not have said so loudely that he considers the others idiots' } \\
& \text { b. ICP Daß er die anderen für Deppen hält] hätte Peter nicht so laut sagen } \\
& \text { sollen }
\end{aligned}
$$

I assume that the $d a \beta$-CP can arise to the left of the verb only under the condition that it is contained in an NP-shell ${ }^{14}$. In other head final languages with extraposition, the facts are less subtle: Bengali je-clauses or $k i$-clauses both in Hindi and Turkish never appear in positions to the left of the verb, although these languages are very permissive as far as scrambling and topicalization are concerned ${ }^{15}$. There is reason to believe that je/ki-clauses have never been to the left of the verb, and that they cannot be raised from the righthand position either. It seems very often to be the case that lefthand and righthand CPs have distinctly different properties, for example different complementizers. Thus, there seem to be good reasons not to assume literal generation of $\mathrm{CP}$ in situ and subsequent extraposition followed by trace deletion. The actual process rather seems to be that there is a pronoun in situ that may get deleted, and that after deletion of this pronoun the righthand base adjoined CP "acquires" argument status. What remains, however, is that deletion of a position yields argument shift.

Let me close this section with a note on the historical development of clausal subordination. It is a widely held opinion among Indoeuropeanists that fully grammaticalized clausal subordination (hypotaxis) is a later phenomenon than coordination (parataxis). The idea is roughly that complex sentences arise first as "text" in the sense that one simplex sentence contains a demonstrative pro-form that refers to the following sentence where the following sentence is often a report of direct speech. Imagine now that in the course of time the pro-form in the first sentence disappears, and that as a consequence the following report of direct speech acquires the role of indirect speech. This is the analysis that Hermann Paul 
may have had in mind when he wrote in Prinzipien der Sprachgeschichte (1880:145):

Ein wichtiger Schritt zur Erzeugung komplizierterer [Satz-, J.B.] Gebilde war, dass das Objektsverhältnis auf einen Satz übertragen wurde.

An important step in the creation of more complex sentence structures was that the object relation was extended to sentences.

Quite obviously, übertragen (transfer) can only mean that the object relation was first defined for a nominal element which then disappeared such that the object relation was transferred to the phrase that was referred to by (or coindexed with) the original object ${ }^{16}$.

If this view of the diachrony of clausal subordination is correct, it gives a plausible perspective of the fact that in Bengali extraposed CPs are headed by je which is homophonous with the relative operator $j e$ that appears in righthand relative clauses. Consider the sentence in (31a) where the je-clause is linked to a dummy DP that remains in object position. Here the presence of $j e$ is obligatory, whereas it is optional in (31b) where the dummy DP is deleted.

(31) a. chele-Ta [e kotha] jan-e na [*(je) baba aS -be] boy CL this speech know-3 not COMP father come-FUT3 'The boy does not know it that his father will come'

b. cheleTa jane na [(je) baba aSbe]

There is some controversy whether je should be considered to be a complementizer or some operator that has been moved to SpecCP${ }^{17}$. The fact that it can be missing in (31b) suggests that the verb governs the extraposed $\mathrm{CP}$ directly and that for this reason the empty complementizer can be identified ${ }^{18}$. Another piece of evidence comes from Assamese, a closely related language. As Madhumita Barbora (p.c.) points out to me, a genuine Wh-operator may move to SpecCP across je. In this case je must be a head:

$$
\begin{aligned}
& \text { moi ne-janu [kak je bill-e juwal kali } e_{i} \text { dekhisil] } \\
& \text { I NEGknow who cOMP Bill } \text { NOM }_{\text {Nosterday }} \text { seen-has } \\
& \text { ASSAMESE } \\
& \text { 'I don't know who Bill has seen yesterday' }
\end{aligned}
$$

The present analysis has a number of advantages: First, as far as CPs with argument status are concerned, it is unnecessary to search for a motivation for rightward movement because nothing has been moved if $\mathrm{CP}$ is originally adjoined to VP and acquires A-status only by means of deletion. This is what I have called argument shift. Secondly, since CP now ends up being L-marked (although in the "wrong" direction), there is a reason why in German overt movement from such CPs is attested. Under the classical extraposition approach, Wh-movement has to 
apply before extraposition because in German Wh-movement from adjuncts is generally not possible $e^{1}$. Thirdly, DPs which have been moved outside VP for formal licensing at LF now c-command and can thus bind into CP. This yields another major result that is also achieved by asymmetric c-command, but now without subscribing to the general philosophy of Kayne's (1993) Linear Correspondence Axiom (LCA). Fourth, focusing particles which are heads outside VP will c-command CP. This yields the desirable result that they can associate with a focus constituent in CP. Recall that the classical extraposition analysis is forced here to the assumption of reconstruction. The fifth point does not seem to be an advantage: The parametric option of head finality declares $\left[\mathrm{X}_{\mathrm{X}}, \mathrm{X}^{\circ} \mathrm{YP}\right]$ as deviant. This is in significant disagreement with Kayne's theory of basic word order uniformity. I will show in the next section that this is the key to a straightforward explanation of the massive scope differences between SVO- and SOV-languages that have been pointed out in sections 3 and 4 .

\section{VP as a directionality barrier}

I want to argue now that in a V-final language like Bengali or German, VP becomes a barrier for the material that it dominates such that this material appears on the non-canonical side of the verb. The definition of barrier given in (33) is designed in such a way as to capture cases in which a phrase is not selected; the novelty is that selection per se is not enough to void barrierhood because selection must in addition be canonical selection. "Canonical" should mean that in a headinitial language the complement is selected to the right of the head, whereas in a head-final language the complement is selected to the left of the head ${ }^{20}$ :

(33) Barrier

$\mathrm{XP}$ is a barrier for YP if either (i) or (ii) holds:

(i) XP is not selected by a head and does not exclude YP

(ii) $\mathrm{XP}$ includes $\mathrm{YP}$ and $\mathrm{X}$ is a head that selects $\mathrm{YP}$ in the non-canonical direction

(34) Exclusion (Chomsky 1986a:9)

$\alpha$ excludes $B$ if no segment of $\alpha$ dominates $B$

Inclusion

$\mathrm{XP}$ includes $\alpha$ if $\alpha$ is dominated by $\mathrm{X}^{\prime}$

"Mixed" languages like Dutch and German are interesting candidates to test this proposal. As I have shown in Bayer (in press), the deviation from head-finality in the syntax of PP has immediate consequences: P-stranding is impossible because the object of $\mathrm{P}$ is included in PP on the "wrong" side. Thus, despite the fact that 
PP may be selected, the DP-object of P cannot be extracted. It may be extracted, however, if it is not included in PP. According to (35), this is the case when it is in SpecPP. It is thus correctly predicted that so-called R-pronouns can be extracted from $P P$.

Let us now turn to the V-system and see what (33) can do for us in connection with the argument shift analysis developed above. There are two important aspects of the argument shift analysis: (i) deletion of the original A-position removes the possibility of reconstruction i.e., the only way of licensing an argument after deletion is to license it directly; (ii) the originally base adjoined category ends up being included in VP. In OV-languages like Bengali, Dutch, German, Hindi etc., the effect of this is that after deletion VP looks essentially like (36) where " $\Rightarrow \mathrm{X}$ " should indicate the $\mathrm{X}^{\prime}$-category that is actually yielded by the process of deletion:

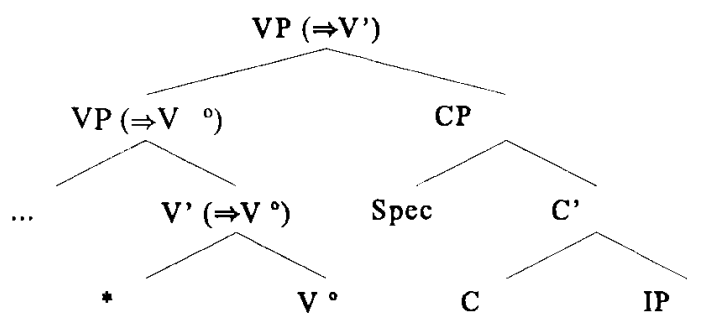

The V-projection is now a directionality barrier for anything included in it on the non-canonical side. Given that the verb selects its object canonically to the left in Hindi and Bengali, we predict that the matrix-VP will be a barrier for any operator that appears in a righthand CP, and that this state of affairs does not change when $\mathrm{CP}$ can be shown to be truly selected by $\mathrm{V}^{\circ}$. Thus, the lack of wide scope of kyaa ("what") in (11), tum jante ho [CP ki usNE kyaa kiyaa]? "You know what he did" is expected. The same holds for ke ("who") in the Bengali example in (12), ora Suneche [ke aSbe], "They heard who will come". The Bengali example in (13), ora [[ke aSbe] (bole)] Suneche where the object-CP remains in canonical position is predicted to be potentially ambiguous because $\mathrm{CP}$ is now included on the canonical side of the verb Sona- ("hear"). This prediction is correct. The same holds for the cases in (14) and for the Marathi examples in (15).

Let us now turn to the scope effects that were observed in the syntax of focusing particles, especially only. (16), We are required to study only SYNTAX, is ambiguous. The phrase only SYNTAX may target either SpecPrtP in the dependent clause or in the matrix clause. The second option is a consequence of the fact that $\mathrm{CP}$ is selected by V on the canonical side of the verb. In the German examples in (17), Man hat uns gezwungen nur SYNTAX zu studieren and Es wurde verlangt, daß wir nur SYNTAX studieren, this ambiguity has disappeared as expected. The phrase nur SYNTAX may move to SpecPrtP in the dependent clause 
but, due to the exceptional selection to the right of $\mathrm{V}^{\circ}$, it may not move any further. The same situation holds in the contrast between Italian and German that appears in the examples (18) and (19). Consider now the data in (20), He asked only what John ate and He said only that John is sick. These are in sharp contrast with the German data in (25), *weil ich gefragt habe, nur was Hans gegessen hat and *weil er gesagt hat, nur daß Hans krank ist. If my views about the LF of particle constructions are on the right track, [nur $\mathrm{CP}]$ must undergo movement to SpecPrtP as shown in (22) above. This is possible in English and it is obviously possible in Italian where the $\mathrm{CP}$-object remains on the canonical side of the verb, but not in German. As a consequence, the focusing particle cannot be licensed in the German examples. If we adopt the reasoning of the Minimalist Program, the derivation will crash if some element remains that cannot be interpreted. Under the plausible assumption that nur makes a truth-conditionally relevant contribution to the sentence meaning, we can say that failure of moving [nur CP] to SpecPrtP will leave nur without scope and thus uninterpreted. Therefore, the derivation will crash in the post-Spell-Out domain of the grammar. The Italian-German contrast seen between (23) and (24c) is explained along the same lines. Consider finally the German example in (26), weil die Kinder geweint haben [nur wenn die Eltern weggehen wollten], "because the children wept only if the parents wanted to leave". The wenn-clause is an adjunct to VP; thus, it is not included in VP, and VP cannot be a barrier and therefore not a directionality barrier. As a consequence [nur CP] can move into the Prt-projection associated with the matrix clause.

\section{Conclusion}

The present theory of CP-extraposition as argument shift has a number of advantages which in my view make it more attractive than the classical extraposition approach, but also Kayne's theory of basic word order uniformity. The arguments against the older extraposition account should be obvious. The present theory is in certain respects closer to Kayne's theory. The clearest difference is that Kayne's theory must take the order $\mathrm{V}+\mathrm{CP}$ as basic because HEAD COMPLEMENT order is the only one that is allowed in his theory of asymmetric c-command. Directionality of government can only be to the right; OV-order must be the result of raising. Word order variations that have hitherto been taken to be the result of parametrical choice are trivialized in this theory. Leftward movement of an object of $\mathrm{V}$ is the result of a "strong" feature that must be checked before Spell-Out. In those languages where objects remain to the right of the head, the object must have a "weak" feature whose checking can be postponed to the postSpell-Out domain of the grammar. Unless additional stipulations are added, this theory is incapable of addressing the scope differences we have observed between $\mathrm{V}$-final and V-initial languages. Why is this so? LF-movement is the paradigm 
case for procrastinated movement. Thus, if $\mathrm{V}+\mathrm{CP}$ order reflects a law of $\mathrm{UG}$ in all languages in which it is attested, namely asymmetric c-command and weakness of the feature on $\mathrm{CP}$, the scope differences referred to above are not expected at all: All languages should allow operator raising from $\mathrm{CP}$ or raising of $\mathrm{CP}$ itself if $\mathrm{CP}$ is quantified as is the case with [only/nur $\mathrm{CP}]$. The alternative theory developed above assumes a structure that is incompatible with asymmetric c-command. It assumes base-adjunction of CP to the right of VP. The basic canonical order of selection retains a leftward orientation in head-final languages. The result that an "extraposed" CP is c-commanded by material in the matrix clause derives from the fact that this material moves to positions "higher" than VP. The result that an "extraposed" object-CP behaves in many ways like a direct argument of the verb derives from the fact that its original object position is deleted, and selection - if it should apply at all - must be directed to the non-canonical side. With the introduction of a notion of barrier that is sensitive to directionality of elementary selection, we could derive the scope differences in a simple way from the parametric choice of directionality. Of particular interest is here that certain modern Indo-Aryan languages such as Bengali, Marathi and Oriya show CPcomplements in situ as well as others which must have emerged from adjuncts whose coindexed argument has been deleted. While the former show transparency for Wh-movement at LF, the latter are solidly opaque. It appears that the analysis of extraposition as A-shift is also supported by diachronic evidence about the grammaticalization of subordination.

I have been silent about one important question: If in a head-final language VP is a barrier for everything included in VP on the right side of V, how is it possible for German to have Wh-movement? I have given an answer in Bayer (in press) which culminates in the conclusion that German has chain composition of Wh-chain links but nothing like literal $W h$-movement. Space limitations prevent me from going into these matters here.

\section{Notes}

1. What is presented here is part of a larger study of directionality effects in syntax and Logical Form, Bayer (in press).

2. See also Singh (1980) for Bengali; as far as I can see, this distribution must be close to a language universal.

3. See especially Davison (1988), Mahajan (1990), Srivastav (1991 a, b).

4. This is essentially the approach taken by Mahajan (1990) and Srivastav (1991a, b). 
5. One difference between Hindi and Bengali is that the latter does not allow the presence of the complementizer $j e$ if there is a $W h$-expression in CP. Notice, however, that the status of $j e$ as a complementizer is a matter of debate; (Bal 1990 and Bayer 1995; in press). Here I assume without discussion that Bengali CPs may be headed by a zero complementizer, and that the Wh-phrase moves to SpecCP at LF.

6. This reading is signalled by a slight stress on the Wh-element and a rising contour as is normally the case for interrogatives. Notice that such prosodic manipulations could never turn cases like (12) into a direct question.

7. Ayesha Kidwai and Probal Dasgupta (p.c.) point out that in certain contexts Bengali bhab may be interpreted as "ponder" or "wonder" in which case a +Wh marked complement is possible. In the present example such a possibility does not arise.

8. This is incompatible with Cheng's (1991) Clausal Typing Hypothesis, which requires that clauses are universally marked for the semantic type they belong to. For the Indo-Aryan Wh-in-situ languages this hypothesis can only be maintained if we assume zero Wh-scope markers. This is very implausible. But even if it is maintained, the next question will be why a zero $W h$-scope marker cannot give rise to wide scope interpretation in (11), (12), (14b) and (15b).

9. Most authors agree that Chinese is typologically an SVO-language.

10. Notice that in German CPs of this sort can easily be topicalized:

(i) [Nur was Hans gegessen hat] habe ich gefragt

(ii) [Nur daß Hans krank ist] hat er gesagt

(iii) [Nur ob ich das Examen bestanden hätte] hat mich meine Mutter am Telefon gefragt

If we assume a fixed functional position for a head $\mathrm{Prt}^{\circ}$ to the left of VP, [nur CP] can move to SpecPrtP from an underlying position to the left of $\mathrm{V}$. As far as the proper representation of the scope of nur is concerned, the LF of (i) looks as in (iv):

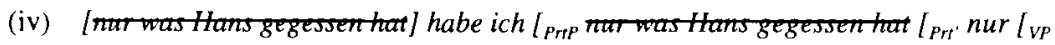
[nar was Hans gegessen hat] gefragtl]]

If an extraposed CP can reconstruct into its basic position, as Büring and Hartmann crucially assume in order to cope with the binding facts we referred to in section 1 , it remains unclear what should block a similar derivation in that case.

11. In fact, there are cases where the right semantic ( $\theta$-)role is not available unless it is assigned compositionally by the ultimate projection of the $\mathrm{V}$-system. This can clearly be observed in VPs which are headed by modals:
(i) daß3 Franz Klavier spielt
$($ Franz $=$ AGENT $)$
that
Franz Klavier
Franz piano
plays
(ii) $d a \beta$
Franz Klavier
spielen
kann
(Franz $\neq$ AGENT)
that Franz piano
play
can 
12. See Bennis (1986) for details with the main examples coming from Dutch.

13. Notice that $\mathrm{I}$ do not assume pro drop. Such an analysis has been envisaged for Hindi by Srivastav (1991a, b) which makes sense because Hindi is a language with object drop. It cannot be maintained for German because German is not a language that licenses pronominal zero objects.

14. See Kiparsky \& Kiparsky (1970) as well as Müller \& Sternefeld (1991) for an analysis along these lines. Note, however, that these authors use the NP-shell analysis also for extraposed CPs. Their purpose is to account for certain semantic differences and for the bridge verb or non-bridge verb character of clause-embedding verbs. Direct evidence in favor of an NP-shell analysis in my sense would be that DPs to the left of V are islands while those to the right are not. The islandhood of CPs follows then from the Complex-NPConstraint. Indirect evidence is that V2-clauses are banned from the scrambling region ( ${ }^{*}$ Peter hätte $\left[_{\mathrm{CP}}\right.$ er hielte die anderen für Deppen] nicht so laut sagen sollen) and very much constrained in topicalized position while they make perfect extraposed complements (Peter hätte nicht so laut sagen sollen $\left[_{\mathrm{CP}}\right.$ er hielte die anderen für Deppen]). The reason seems to be that the C-head $d a \beta$ is compatible with nominal features, while a C-head that is filled with the finite verb is certainly not. See Webelhuth (1989) among others.

15. For Hindi see Davison (1993); thanks to Jaklin Kornfilt (p.c.) for pointing out the Turkish facts.

16. Paul (1886:147) mentions in this context explicative sentences which are adjuncts to a noun such as in (i), but points to the high frequency with which such relation holds between the sentence and a pronoun as in (ii):

(i)a. er sprach die Worte: das tue ich niemals
he spoke the words: this do I never
b. ein sonderbarer Zufall hat sich gestern
$\begin{array}{lll}\text { a strange } & \text { accident has REF yesterday happened } \\ \text { es begegneten } & \text { sich zwei Freunde... } \\ \text { there met } & \text { REF two friends }\end{array}$

(ii)a. das ist sicher, er wird es nicht wagen

this is sure he will it not venture
es ist besser, du gehst
it is better you go

In these examples of sentential subordination, the order of constituents follows the V2 pattern of root clauses.

17. See Bal (1990) who argues in favor of the latter analysis.

18. See Stowell (1981) on an analogous situation in English.

19. See Büring \& Hartmann (1994) where such an analysis is still defended. 
20. Earlier proposals of this kind are found in Kayne's (1983) theory of connectedness and in Koster's (1987) theory of domains and dynasties. For reasons of space I cannot turn to various complications that appear w.r.t. the syntax of NP and DP. A fuller treatment is given in Bayer (in press).

\section{References}

Baker, M. 1988. Incorporation: $A$ Theory of Grammatical Function Changing. Chicago: Chicago University Press.

Bal, B.K. 1990. COMP and Complementizers in Oriya and English. Doctoral dissertation. Hyderabad (India): Central Institute of English and Foreign Languages.

Bayer, J. 1995. "On the origin of sentential arguments in German and Bengali". Studies in Comparative Germanic Syntax ed. by H. Haider, S. Olsen \& S. Vikner. Dordrecht: Kluwer.

Bayer, J. 1996. Directionality and Logical Form: On the Scope of Focusing Particles and Wh-in-Situ. Dordrecht: Kluwer.

Bennis, H. 1986. Gaps and Dummies. Dordrecht: Foris.

Büring, D. and K. Hartmann. 1994. "Doing the right thing - extraposition as a movement rule". Sprachwissenschaft in Frankfurter, Arbeitspapier 13.

Cheng, L. 1991. On the Typology of Wh-Questions. Ph.D. dissertation, MIT Cambridge, Massachusetts.

Chomsky, N. 1993. "A minimalist program for linguistic theory". The View From Building 20: Essays in Linguistics in Honor of Sylvain Bromberger ed. by K. Hale \& S.J. Keyser. Cambridge Massachesetts: MIT Press.

Davison, A. 1988. "Operator binding, gaps, and pronouns". Linguistics 26.181-214.

Davison, A. 1993. Lexical projection, Case and Clause Adjunction: Another View of "Case resistance". Ms., University of Iowa.

Hoekstra, T. 1987. "Extrapositie en SOV". Tabu 17.133-142.

Iatridou, S. \& A. Kroch. 1992. "The licensing of CP-recursion and its relevance to the Germanic Verb Second Phenomenon". Working Papers in Scandinavian Syntax 50:1-24.

Kayne, R. 1983. "Connectedness". Linguistic Inquiry 14.223-249.

Kayne, R. 1993. The antisymmetry of syntax. Ms., CUNY, New York (published 1994 in expanded form by MIT Press).

Kiparsky, P. \& C. Kiparsky. 1970. "Fact". Progress in Linguistics by M. Bierwisch \& K. Heidolph. The Hague: Mouton.

Koster, J. 1987. Domains and Dynasties: The Radical Autonomy of Syntax. Dordrecht: Foris.

Longobardi, G. 1991. "In defense of the Correspondence Hypothesis: Island effects and parasitic constructions in Logical Form" ed. by Huang \& May.

Mahajan, A. 1990. The A/A-bar Distinction and Movement Theory. Ph.D. dissertation, MIT Cambridge, Massachusetts.

Müller, G. \& W. Sternefeld. 1991. Extraction, lexical variation, and the theory of barriers. Ms. University of Konstanz.

Paul, H. 1980. Prinzipien der Sprachgeschichte, 9th ed. 1975. Tübingen: Niemeyer. 
Singh, UT.N. 1980. "Bole: An Unresolved Problem in Bengali Syntax". Indian Linguistics 41.188-195.

Srivastav, V. 1991a. WH Dependencies in Hindi and the Theory of Grammar. Ph.D. dissertation. Cornell University, Ithaca, NY.

Srivastav, V. 1991b. "Subjacency effects at LF: The case of Hindi WH". Linguistic Inquiry 22.762-769.

Stowell, T. 1981. Origins of Phrase Structure. Ph.D. dissertation. MIT Cambridge, Massachusetts.

Taglicht, J. 1984. Message and Emphasis: On Focus and Scope in English. London: Longman.

Wali, K. 1988. "A note on WH questions in Marathi and Kashmiri". Cornell Working Papers in Linguistics 8.161-180.

Webelhuth, G. 1989. Syntactic Saturation Phenomena and the Modern Germanic Lan guages. Ph.D.dissertation. University of Massachusetts, Amherst Massachusetts.

Zwart, J.-W. 1993. Dutch Syntax: A Minimalist Approach. Doctoral dissertation, University of Groningen. 